\title{
Qualidade de cultivar de cana-de-açúcar, sob formas de colheita e tempos de amostragem
}

\section{Quality of cultivar of sugar cane, under forms of harvest and time of sampling}

\author{
Uriel Calisto Moura Pessôa $a^{1}$, Wemerson Silva Oliveira ${ }^{2}$, Anielson dos Santos Souza ${ }^{3}$, Thiago Alves Pimenta ${ }^{4}$, Alberto de $^{2}$ \\ Andrade Soares Filho 5
}

Resumo: Objetivou-se avaliar as formas de colheita e o tempo em que a cana-de-açúcar pode permanecer no campo sem que ocorram perdas na qualidade da matéria prima para processamento industrial. O experimento foi instalado na fazenda Espírito Santo pertencente à Companhia Usina São João, localizada na Zona da Mata paraibana. Foram realizadas três formas de colheita (FC): A FC-1 refere-se à cana-de-açúcar in natura; A FC-2 refere-se à cana-de-açúcar que passou por um processo de queima; A FC-3 refere-se à cana-de-açúcar que passou pelo processo de queima, sendo cortadas determinadas horas após a queima $(0,12,24,36,48,60,72,84,96,108$ e 120 horas). As amostras foram analisadas no Laboratório de Pagamento de Cana pelo Teor de Sacarose (LPCTS) da Companhia Usina São João. Os Parâmetros tecnológicos da cana-de-açúcar que foram analisados são: Sólidos solúveis - ${ }^{\circ}$ Brix (\%), Teor de sacarose - Pol (\%), Fibra industrial (\%), Pureza (\%) e Açucares Redutores Totais- (ART kg/t). O melhor comportamento foi verificado na CF-1, com superioridade nos parâmetros, ${ }^{\circ}$ Brix $(\%)$, Pol (\%), Pureza (\%), ATR e menor comportamento no parâmetro PB (\%). O melhor tempo entre a colheita e processamento para as formas de colheitas CF-1 e CF-2 é de período 36 horas.

Palavras-chave: Cultivar BR92579, Pós-Colheita, Deterioração

Abstract: The experiment was installed on the Holy Spirit farm, belonging to the Saint John Mill Company, located in the Paraíba Forest Zone. The objective of this study was to evaluate the harvest forms and the time when the sugar cane can stay in the field without losses in the quality of the raw material for industrial processing. It were studied three ways of harves (FC): The FC-1 refers to the natural sugar cane. The FC-2 refers that have passed through burning process. The FC-3 refers to the sugar cane that have passed through burning process, being cut off at certain hours after burning $(0,12,24,36,48,60,72,84$, 96, 108 and 120 hours). The samples were analyzed at the Cane Payment Laboratory by Sucrose Content, in portuguese, LPCTS, belonging to the Saint John Mill Company. The technological parameters of the sugar cane that were analyzed, are: Soluble solids- Brix (\%), Sucrose content - Pol (\%),industrial fiber (\%), Purity (\%) and Sugar total reducers - (ART kg/t). The best behavior was verified at the CF-1, with superiority in the parameters, Brix (\%), Pol (\%), Purity (\%), ATR and less behavior in the parameter PB (\%).The best time between harvesting and processing for crop forms CF-1 and CF-2 is the period of 36 hours.

Keywords: Cultivar BR92579; Postharvest, Deterioration.

\footnotetext{
*Autor para correspondência

Recebido para publicação em 11/08/2016; aprovado em 22/10/2016

${ }^{1}$ Graduando em Agronomia - UFCG/CCTA - Universidade Federal de Campina Grande, Pombal-PB. E-mail: uriel.pessoa2@ gmail.com

${ }^{2}$ Bacharel em Agronomia - UFCG/CCTA - Universidade Federal de Campina Grande, Pombal-PB. E-mail: silva.wemersonsilva@gmail.com

${ }^{3}$ Eng. Agr. D. Sc., Professor da Unidade Acadêmica de Ciências Agrárias - UFCG/CCTA - Universidade Federal de Campina Grande, Pombal-PB. E-mail: anielson@ccta.ufcg.edu.br

${ }^{4}$ Graduando em Agronomia - UFCG/CCTA - Universidade Federal de Campina Grande, Pombal-PB. E-mail: tpimenta62@ gmail.com

${ }^{5}$ Graduando em Agronomia - UFCG/CCTA - Universidade Federal de Campina Grande, Pombal-PB. E-mail: alberto.asf10@ bol.com.br
} 


\section{INTRODUÇÃO}

A cana-de-açúcar pertence à família Poaceae, e gênero Saccharum, originária do sudeste da Ásia, que foi introduzida no Brasil pelos colonizadores portugueses (KLEIN, 2010). Atualmente é uma das culturas de maior importância socioeconômica no Brasil (RODRIGUES et al., 2012), sendo cultivada em todas as regiões, devido a sua adaptação as condições edafoclimáticas do país. Condições estas que favorecem o manejo da cultura afetada manejo pós-colheita, alterando as características qualitativas da cana-de-açúcar.

As características que definem a qualidade da cana-deaçúcar reúnem os fatores intrínsecos (teores de sacarose, açúcar redutores, fibras, composto fenólicos, amido, cor do caldo, ácidos aconíticos e minerais), e os fatores extrínsecos são (terra, pedra, restos de cultura, planta daninha, compostos produzidos por microrganismos devido a sua ação sobre os açúcares do colmo) (AMORIM, 2003).

Os fatores intrínsecos são afetados pelos fatores extrínsecos, associados ao tempo de exposição e a ação da queima, que potencializa a perda da qualidade da matéria prima. A colheita da cana crua propicia melhoria da qualidade tecnológica industrial da cana-de-açúcar, com redução dos custos industriais referentes à lavagem da cana e aumento da produtividade agrícola e a longevidade das soqueiras.

A eficiência do processo industrial de recuperação do açúcar depende da qualidade da matéria prima entregue na unidade industrial, que é medida usando os parâmetros tecnológicos da cana-de-açúcar. Os principais parâmetros tecnológicos relacionados à qualidade da cana-de-açúcar pós queima/corte são Pol, Pureza, ATR (açúcares redutores totais) na cana, teor de açúcares redutores, \% de fibra e tempo de armazenamento (VASCONCELOS, 2010), que são influenciados pelo tempo de armazenando, com reduzindo os teores de pureza e aumentando os teores de sólidos solúveis e consequentemente dos teores de açúcar redutores, sendo um ponto negativo para o processamento principalmente na etapa de clareamento do açúcar.

A eficácia no processo de colheita é fundamental para a qualidade do produto final. Com necessidade de conhece a forma de colheita correta e o tempo em que a cana-de-açúcar poderá fica no campo sem alterar negativa e/ou econômica no processo industrial. Considerando que a matéria prima da agroindústria canavieira é produzida no campo e sua participação na formação dos custos de açúcar e do etanol gira em torno de 60\% (VEIGA FILHO, 1999). Com isso, é fundamental que o processo de colheita seja realizado de forma correta e no tempo certo para garantir que os parâmetros tecnológicos da cana-de-açúcar não sejam alterados negativamente.

Objetivou-se com o trabalho avaliar as formas de colheita e o tempo em que a cana-de-açúcar pode ficar no campo sem que haja perdas na qualidade da matéria prima para processamento na indústria.

\section{MATERIAL E MÉTODOS}

O experimento foi instalado na fazenda Espírito Santo, localizada no município de Cruz do Espírito Santo-PB, está fazenda pertence à Companhia Usina São João, empresa que atua na fabricação de açúcar e etanol, com áreas distribuídas entre as cidades de Santa Rita-PB, Cruz do Espírito Santo-PB, Sapé - PB, São Miguel do Itaipu-PB e Conde - PB.

A Companhia Usina São João, possui uma área plantada de cana-de-açúcar, aproximadamente 8.000 ha, com média por ha de $55 \mathrm{t}$, na safra de 2012/2013, que produziram 500.000 t de cana-de-açúcar.

O Laboratório de Pagamento de Cana pelo Teor de Sacarose (LPCTS) da Companhia Usina São João, foi usado para realização das análises. O LPCTS localiza-se na fazenda Central, pertencente à Companhia Usina São João. A fazenda Central encontra-se no território do município de Santa RitaPB.

O delineamento experimental utilizado foi o de blocos ao acaso em esquema fatorial $3 \times 11$, sendo os fatores: três manejos de colheita, e onze tempos de análise com três repetições, totalizando 99 parcelas, sendo as formas de colheita (FC): cana crua FC-1 (Figura 1A), cana queimada FC-2, (Figura 1B) e cana queimada e mantida de pé, FC-3, os tempos para a análise foram os seguintes: $0,12,24,36,48$, 60, 72, 84, 96, 108 e 120 h (Figura 1C).

Foram analisados os parâmetros tecnológicos, no período de 120 horas, com análise a cada 12 horas, com início a zero hora. Nas formas de colheitas FC-1 e FC-2 foram coletadas as canas-de-açúcar apenas uma vez no talhão de origem, e organizadas em montes conforme é realizado no processo de colheita. Na FC-3, as canas-de-açúcar foram queimadas, mas, não aconteceu o corte imediato após a queima. Dessa forma CF-3 foram coletadas as canas-deaçúcar onze vezes, uma coleta, para cada envio (Tabela 1).

Figura 1. 'A': Cana-de-açúcar in natura e cortadas (CF-1); 'B' Cana-de-açúcar queimada e imediatamente cortada (CF-2) e 'C' Cana-de-açúcar queimada e não imediatamente cortada CF-3)
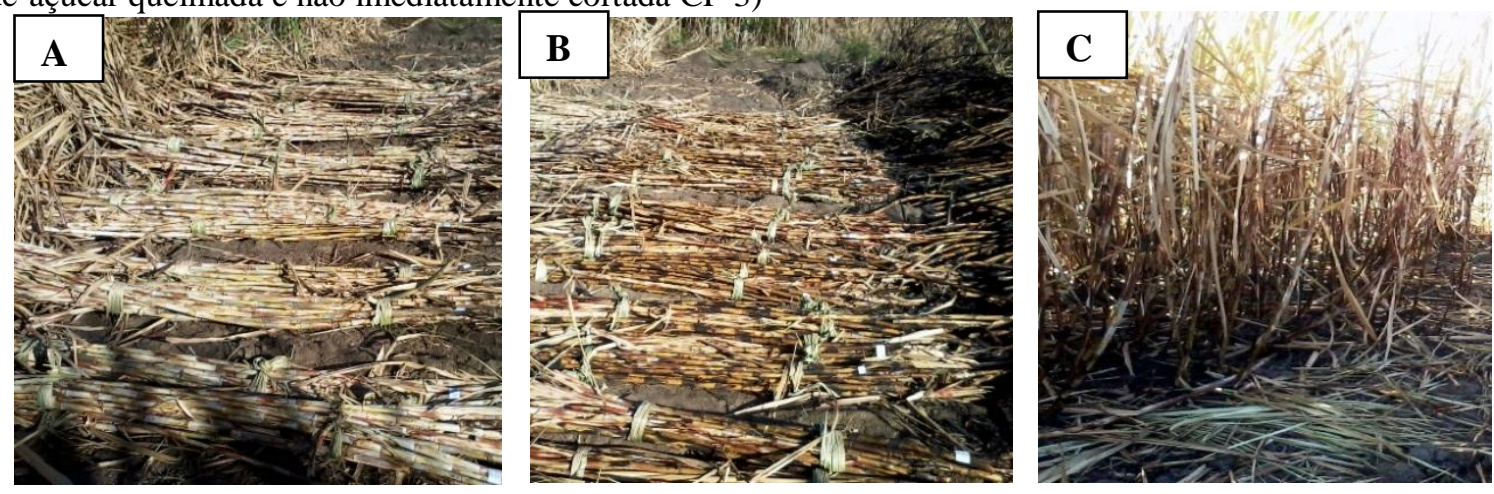
Tabela 1. Programação de envios das amostras das canas-deaçúcar, para o Laboratório de Pagamento de Cana pelo Teor de Sacarose (LPCTS) da Usina São João

\begin{tabular}{cc}
\hline Envio das amostras (h) & $\begin{array}{c}\text { Período da amostra no } \\
\text { campo }(\mathrm{h})\end{array}$ \\
\hline $06: 00$ & 0 \\
$18: 00$ & 12 \\
$06: 00$ & 24 \\
$18: 00$ & 36 \\
$06: 00$ & 48 \\
$18: 00$ & 60 \\
$06: 00$ & 72 \\
$18: 00$ & 84 \\
$06: 00$ & 96 \\
$18: 00$ & 108 \\
$06: 00$ & 120 \\
\hline
\end{tabular}

As parcelas experimentais possuíam $1,25 \mathrm{~m}^{2}$, com dimensões de 2,5 $\mathrm{m}$ de comprimento por $0,5 \mathrm{~m}$ de largura. $\mathrm{O}$ bloco foi composto por 33 parcelas, sabendo que a forma de colheita CF-3 não ficou no bloco, pois se objetivou averiguar o comportamento da cana-de-açúcar queimada e não imediatamente cortada, com isso as amostras ficaram 'em pé' no talhão de origem. As amostras para as formas de colheita CF-1 e CF-2 foram distribuídas nas parcelas ficando organizadas em montes, para simular o que ocorre no processo normal de colheita. Foi escolhido um talhão que estava sendo cultivada a variedade BR92579. Cada parcela recebeu um metro linear de cana-de-açúcar (12 colmos). Após a queima afetou-se a confecção das amostras, com as coletas no talhão respeitando a bordadura de 1 metro.

Cada forma de colheita por envio era composta por três montes, um em cada bloco. Cada monte era composto por 12 canas, e cada um representar uma repetição, somando três montes por forma de colheita enviada ao laboratório a cada 12 h. Assim uma forma de colheita durante o experimento possuíam 396 canas-de-açúcar e todo o experimento 1.188 canas-de-açúcar.

\section{Características da cultivar}

A cultivar RB 92579, resultou de um cruzamento biparental, tendo cultivar progenitora RB 92579, fecundadas com pólen da cultivar RB72199 (Figura 2). Desde a sua liberação, a RB92579 vem apresentando expressivas elevações das áreas colhidas pelas empresas da região nordeste, em função de suas vantajosas produtividades agroindustriais, de $30 \%$ a $40 \%$ acima das outras que eram mais cultivadas e $60 \%$ acima das variedades cultivadas há duas décadas (RIDESA, 2010).

Figura 2. Genealogia da variedade RB 92579.

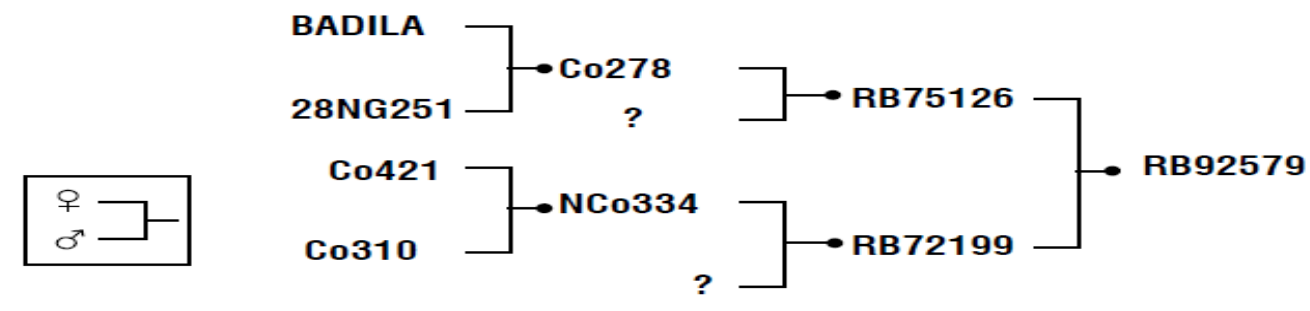

Fonte: RIDESA 2010

A cultivar RB92579, apresenta uma alta eficiência no uso da terra, por proporciona excelente produtividade agrícola, ótimo perfilhamento, bom fechamento da entrelinha, ótima brotação das socarias, garantindo longevidade dos canaviais, seu porte é semi-ereto com ótima colheitabilidade, recomendada para colheita do meio para o final de safra (RIDESA, 2010).

\section{Características avaliadas}

As amostras foram analisadas no Laboratório de Pagamento de Cana pelo Teor de Sacarose (LPCTS) da Companhia Usina São João. Os Parâmetros tecnológicos da cana-de-açúcar que foram analisados foram: Sólidos solúveis Totais - ${ }^{\circ}$ Brix $(\%)$ e Teor de sacarose -Pol $(\%)$,Fibra industrial (\%), Pureza (\%) e Açúcares Redutores Totais- (ART kg/t).

As amostras da área experimental foram transportadas por caminhão, chegando à Companhia Usina São João, onde foram preparadas para serem analisadas no laboratório da empresa. A primeira etapa foi passar as amostras no aparelho desintegrador e em seguida efetuou uma homogeneização manual.

A quantidade de amostras homogeneizadas foi equivalente a $2,0 \mathrm{~kg}$, sendo posteriormente, conduzidas ao
Laboratório, onde foi pesada uma amostra de $0,5 \mathrm{~kg}$ da cana desfibrada e homogeneizada sendo transferida para uma prensa hidráulica para extração do caldo, onde foi submetida a uma pressão constante de $250 \mathrm{kgf} / \mathrm{cm}^{2}(24,5 \mathrm{MPa})$ durante o período de um minuto. A parte fibrosa resultante da prensagem foi pesada para fornecer o peso do bolo (bagaço) úmido (PBU). A quantidade de caldo extraído ficou entre 0,250 e $0,300 \mathrm{~L}$ por amostra, sendo esta quantidade filtrada em filtro de papel e utilizada para realização dos ensaios para a determinação do ${ }^{\circ}$ Brix (\%) e da Pol (\%).

A determinação do ${ }^{\circ}$ Brix (\%) foi feita a partir do caldo extraído da cana-de-açúcar efetuada em refratômetro digital provido de correção automática de temperatura e ajuste de campo, devendo o valor final ser expresso a $20{ }^{\circ} \mathrm{C}$.

$\mathrm{O}$ índice de refração que é proporcional ao índice de sólidos solúveis ou ${ }^{\circ}$ Brix é obtido pela Equação 1.

$$
\operatorname{Ir}=\operatorname{Sen}(i) / \operatorname{Sen}(I)
$$

Em que:

Ir - Brix ou teor de sólidos solúveis;

Sen (i) - Seno do ângulo de incidência

Sen (r) - Seno do ângulo de refração. 
Pol do caldo em \% foi determinado com o uso do sacarímetro, aparelho construído para determinar concentração de açucares, oticamente ativos como sacarose. Os princípios da Física que se baseiam são fundamentais nas propriedades da luz e na natureza ondulatório, onde o plano de vibração da luz polarizada linear é desviado ao atravessar uma solução de sacarose.

O índice de refração que é proporcional ao índice de sólidos solúveis ou Pol é obtido pela Equação 2.

$$
\mathrm{C}=100 . \alpha / \text { L. } \alpha . \mathrm{y}
$$

Em que:

$\mathrm{C}=$ concentração de açúcar;

$\alpha=$ ângulo de rotação do plano de vibração da luz polarizada;

$\mathrm{L}=$ comprimento da coluna iluminada de líquido;

$\alpha . \gamma=$ rotação específica.

Foi realizada a correção da leitura para ajustar a temperatura ambiente em torno de $20{ }^{\circ} \mathrm{C}$, utilizando-se a Equação 3.

$$
\mathrm{L} \text { corrigida }=\mathrm{L}[1+0,00000255(\mathrm{~T}-20)] \quad(\text { Eq. } 3)
$$

Em que:

L corrigida $=$ Leitura sacarimétrica corrigida a $20{ }^{\circ} \mathrm{C}$

$\mathrm{L}=$ leitura no sacarímetro;

$\mathrm{T}=$ temperatura laboratório.

Os resultados obtidos de PBU, Brix (\%) e Pol (\%), servem de base para determinar os demais parâmetros (Fibra (\%), Pureza (\%) e ATR) conforme o método CRSPCTS/PB, utilizando soltware Sisagri (sistema de controle e gerenciamento agrícola).

\section{Determinação da Fibra industrial \% da cana-de-açúcar}

O cálculo da fibra industrial \% da cana foi baseado na correlação entre resíduos fibrosos e fibra industrial, determinada experimentalmente segundo a Equação 4.

$$
\text { FIBRA = (100.PS) x (PU.b) / 5.(100-b) }
$$

Em que:

$\mathrm{PS}=$ peso do bolo seco a $105^{\circ} \mathrm{C}$;

$\mathrm{PU}=$ peso do bolo úmido (resíduo fibroso);

$\mathrm{b}=$ Brix do caldo extraído

\section{Determinação da Pureza do caldo}

A pureza foi calculada com a porcentagem de sólidos solúveis totais no caldo extraído, após a determinação dos valores de POL. e ${ }^{\circ}$ BRIX. (Caldas, 1998). A pureza foi determinada pela Equação 5 .

$$
\mathrm{PZA}=\mathrm{POL} \text { caldo } \% /{ }^{\circ} \text { Brix caldo } \%
$$

\section{Determinação Açúcar Total Recuperável ATR}

O Açúcar Total Recuperável da cana foi calculado pela Equação 6.

$$
\mathrm{ATR}=10 \times \mathrm{PC} \times 1,05263 \times 0,905+10 \times \text { ARC } \times 0,905 \text { (Eq. 6) }
$$

Em que:

$10 \times \mathrm{PC}=$ Pol por tonelada de cana

$1,05263=$ coeficiente estequiométrico para a conversão da sacarose em açúcares redutores

0,905 = coeficiente de recuperação, para uma perda industrial de $9,5 \%$ (nove e meio por cento)

$10 \times \mathrm{ARC}=$ açúcares redutores por tonelada de cana.

\section{Análise estatística}

Os dados obtidos nos diferentes tratamentos foram submetidos à análise da variância pelo teste $\mathrm{F}$, e quando verificado efeito significativo às médias dos tratamentos quantitativos foram desdobradas em análise de regressão e em teste de médias (Tukey, 5\%) para os tratamentos qualitativos, de modo isolado para cada parâmetro. A análise estatística foi realizada com o auxílio do programa computacional SAEG V. 5.0 DOS

\section{RESULTADOS E DISCUSSÃO}

No Resumo das análises de variância para os parâmetros ${ }^{\circ}$ Brix $(\%)$, Pol (\%), Pureza (\%), Fibra (\%) e ATR (kg/t), observou-se efeito não significativo da interação entre a forma de colheita e o tempo de armazenamento da cana-deaçúcar (RB 92579). Contudo, nota-se efeito significativo, em todos os parâmetros há nível de $1 \%$ de probabilidade do "tempo de armazenamento", ocorrendo, também, diferenças entre as "formas de colheita", $\mathrm{p} \leq 0,01$, para os parâmetros ${ }^{\circ}$ Brix $(\%)$, POL $(\%)$ e ATR $(\mathrm{kg} / \mathrm{t})$, conforme teste F (Tabela 2), e dessa fonte de variação na Fibra (\%) há 5\% de probabilidade.

Tabela 2. Resumo das análises das variâncias para os dados de Sólidos Solúveis Total - ${ }^{\circ}$ Brix $(\%)$, Teor de sacarose - POL (\%)

\begin{tabular}{lcccccc}
\multirow{2}{*}{ Fontes de variação } & \multirow{2}{*}{$\mathrm{GL}$} & \multicolumn{3}{c}{ Quadrados Médios } \\
\cline { 3 - 7 } & & ${ }^{\circ}$ Brix $(\%)$ & POL $(\%)$ & Pureza $(\%)$ & Fibra $(\%)$ & ATR $(\mathrm{kg} / \mathrm{t})$ \\
\hline Colheita & 2 & $18,73 * *$ & $13,31 * *$ & $13,55 \mathrm{~ns}$ & $1,81 *$ & $567,39 * *$ \\
Tempo & 10 & $5,75 * *$ & $1,97 * *$ & $46,55 * *$ & $2,49 * *$ & $206,61 * *$ \\
Tempo*colheita & 20 & $0.38 \mathrm{~ns}$ & $0,28 \mathrm{~ns}$ & $12,48 \mathrm{~ns}$ & $0,75 \mathrm{~ns}$ & $16,82 \mathrm{~ns}$ \\
Bloco & 2 & $1,25 \mathrm{~ns}$ & $0,82 \mathrm{~ns}$ & $12,23 \mathrm{~ns}$ & $0,99 \mathrm{~ns}$ & $5,708 \mathrm{~ns}$ \\
Resíduo & 64 & 0,41 & 0,26 & 15,99 & 0,51 & 13,33 \\
\hline CV $(\%)$ & & 2,71 & 2,47 & 4,61 & 5,66 & 2,18 \\
\hline Média & & 23,70 & 20,76 & 86,71 & 12,64 & 167,12 \\
\hline
\end{tabular}

$(* *) ;(*) ;(n s)$ significativos a $(\mathrm{p} \leq 0,01)$ e $(\mathrm{p} \leq 0,05)$ e não significativo, respectivamente, pelo teste $\mathrm{F}$.

\section{Teores Sólidos Solúveis Totais - ${ }^{\circ}$ Brix $(\%)$}

Estudando-se o teor de sólidos solúveis totais em função das formas de colheita isoladamente, verifica-se, na forma de colheita CF-1, maior média 24,02\% quando comparado com as demais, CF-2 de $23,94 \%$ e CF-3, onde se obteve $23,06 \%$ (Figura 3A).
Esta superioridade está associada ao não uso do processo de queima do canavial, não ocorrendo perdas de sólidos solúveis totais e, possivelmente sacarose, como poderá ser visto na variável Pol. Estas perdas que ocorreram nas formas de colheita $\mathrm{CF}-3$ e CF-2 podem ter sido ocasionadas pela exsudação da água decorrente da alta 
temperatura proveniente da queima da cana no processo de colheita, já que, segundo Segado et al. (2006), altas temperaturas facilitam o rompimento da parede do colmo, causando a exsudação.

Complementando, nota-se que as médias neste trabalho (Figura 3A) estão superiores as verificadas na literatura, pois Silva et al. (2007) informam que os valores médios de ${ }^{\circ}$ Brix (\%) devem variar de 17 a $23 \%$ do caldo, e Silva et al (2013), verificou médias de ${ }^{\circ}$ Brix (\%), para cana planta de $17,30 \%$, para primeira rebrota $19,27 \%$ e segunda rebrota valor de $19,16 \%$. Esta superioridade esta relacionando o tempo de armazenamento em nível de campo.

$\mathrm{Na}$ forma de colheita CF-3 obteve-se a menor média, mesmo comparada com a forma de colheita CF-2, que também passou pelo processo de queima. Todavia, na forma de colheita $\mathrm{CF}-3$ as plantas foram queimadas e permaneceram no campo até o momento do processamento, o que pode ter reduzido a ação de microrganismo nos colmo longitudinalmente e nos danos mecânicos na base e no ápice da planta, que não sofreram período de espera expostos as condições ambientais.

Estudando-se o ${ }^{\circ}$ Brix $(\%)$ da cana em função do tempo para cada forma de colheita (Figura 3B, C e D), pode-se notar, na $\mathrm{CF}-3$, onde as plantas permaneceram no campo, após queimada, até o momento do processamento, que houve a reativação das atividades fisiológicas da planta, proporcionando a metabolização dos sólidos solúveis. Ocorrendo decréscimo nos valores até 48 horas, fato que não ocorreu nas outras formas de colheita. Ainda, esse comportamento pode refletir no teor de sacarose pela reativação do metabolismo da planta, o que poderá ser visto na Pol.

Valente et al. (2012), estudando o efeito da presença ou ausência de componentes não-colmo e do tempo de estocagem sobre as perdas de massa e concentração de açúcares em cana-de-açúcar, verificaram média de 19,78\% para ${ }^{\circ}$ Brix (\%) na cana-de-açúcar com colmos sem ponteiro e palhas queima. Estes autores também verificaram incremento no ${ }^{\circ}$ Brix $(\%)$ da cana até os 10 dias de armazenamento, convergindo com os resultados observados neste trabalho.

Em geral, o aumento dos valores ${ }^{\circ}$ Brix (\%) podem ter ocorrido devido à desidratação, principalmente nas formas de colheitas CF-1 e CF-2, com aumento superior a $1 \%$ a partir de $36 \mathrm{~h}$, tal aumento com o tempo, provavelmente está relacionando com a perda de líquido do que pelo aumento de sólidos solúveis (TAVARES,1997). O melhor tempo entre a colheita e processamento, neste trabalho, está coerente com a literatura, que recomenda o tempo máximo entre a queima e a moagem da cana-de-açúcar de 24 a 36 h (SIQUEIRA et al, 2012). Resultados semelhantes foram relatados por Ripoli e Ripoli (2004), afirmando que até $36 \mathrm{~h}$ as perdas não são significativas à cana queimada, acrescentando que, ao ser cortada e exposta ao tempo, a cana sofrerá uma desidratação, com perda de peso, intensificando a respiração do colmo com perdas de açúcares e ocorrendo o desenvolvimento de microrganismos que acelerarão a deterioração da cana levando a perdas na qualidade.

Figura 3. 'A': Refere-se as médias das formas de colheitas para o parâmetro ${ }^{\circ}$ Brix (\%); 'B': Refere-se a análise de Regressão Polinomial para o parâmetro ${ }^{\circ}$ Brix $(\%)$ na $\mathrm{CF}-1$; ' $\mathrm{C}$ ': Refere-se a análise de Regressão Linear para o parâmetro ${ }^{\circ}$ Brix $(\%)$ na CF-2;' D’: Refere-se a análise de Regressão Linear para o parâmetro ${ }^{\circ}$ Brix (\%) na CF-3
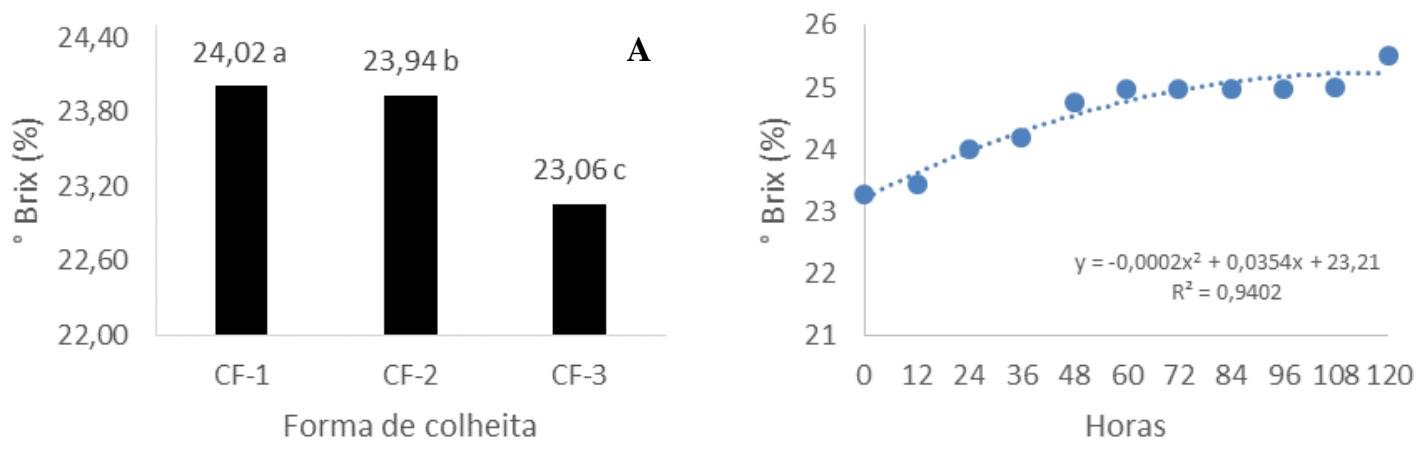

B
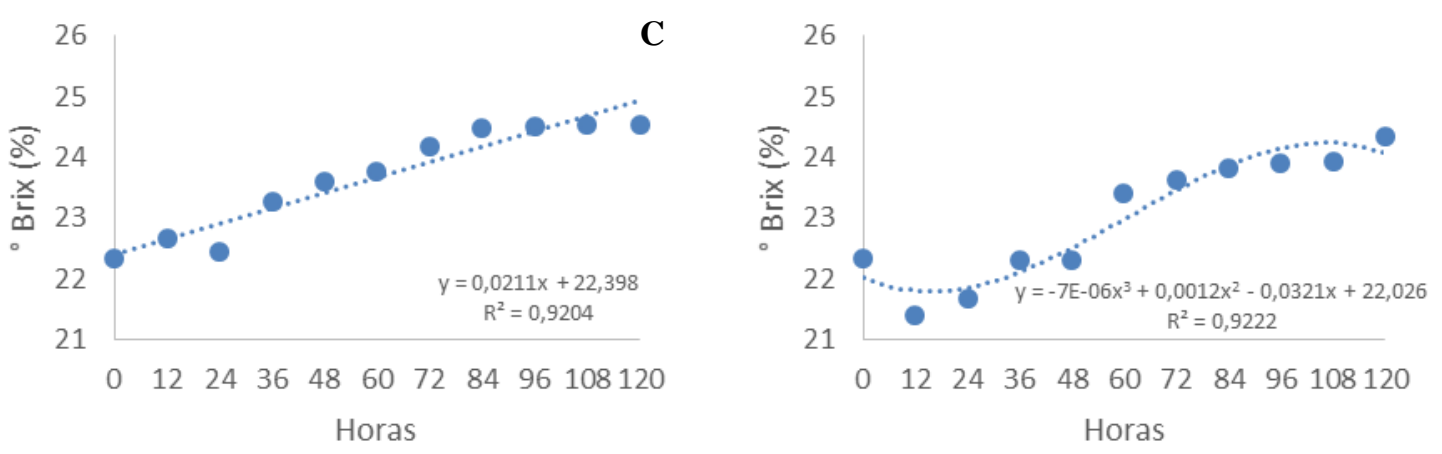


\section{Teor de Sacarose - Pol (\%)}

Estudando-se o teor de Sacarose em função das formas de colheita, verifica-se diferença estatística. Na CF-1 obtevese maior média $(21,47 \%)$, seguida da CF-2 $(20,61 \%)$ e CF-3 com valor médio da Pol (\%) 20,33\%.

A sacarose é um dos sólidos solúveis totais, sendo influenciado pelo comportamento do mesmo deste. Com isso as médias da Pol (\%) se encontram na mesma ordem das verificadas para o ${ }^{\circ}$ Brix (\%) entre as formas de colheitas e sua causa discutida anteriormente, todavia, com diferenças nos valores acrescido com o tempo após a colheita.

Os valores das médias da Pol (\%) estão superiores aos encontrados na literatura, já que Oliveira et al. (2011), estudando a produtividade, eficiência de uso da água e qualidade tecnológica de cana-de-açúcar submetida a diferentes regimes hídricos, verificaram para variedade RB92579, quando obtiveram, no cultivo em sequeiro, valores de Pol (\%) de 18,20\% e, para cultivo com irrigação plena, de $18,80 \%$. Todavia, ao se avaliar as zero hora, os valores da Pol (\%) ficam entre 19,3 e $20,9 \%$ no CF-3 e CF-1, respectivamente, ou seja, semelhantes aos encontrados na literatura, evidenciando-se a influência do tempo de armazenamento em nível de campo.
Ao se analisar a curva de regressão para a Pol (\%) em função do tempo, verifica-se comportamento linear crescente nas formas de colheita CF-1 e CF-3, valores máximos estimados, as 120 e $84 \mathrm{~h}$, quando se obteve uma Pol de 21,88 e 20,60\%. Os acréscimos ocorridos neste trabalho foram provenientes da perda de peso da cana-de-açúcar que proporcionou desidratação, que acarreta aumento no teor de Pol (\%). Resultado semelhante foi verificado por Vasconcelos (2010), afirmando que as perdas de peso na cana-de-açúcar colhida inteira são, principalmente, devido à evaporação de água, o que faz com que a Pol (\%) aumente.

Para a forma de colheita CF-2 houve aumento até o valor estimado de $82,5 \mathrm{~h}$, quando se obteve uma POL de $22,3 \%$, ocorrendo decremento a partir desse ponto. Possivelmente, o aumento da concentração esteja relacionado com o aumento da respiração e desidratação do colmo que ocorre durante o tempo armazenamento em campo, resultando aumento da concentração do soluto.

$\mathrm{Na}$ forma de colheita CF-3, houve aumento da Pol (\%) (Figura 4D) em período onde houve decréscimo do ${ }^{\circ}$ Brix $(\%)$ (Figura 3D), isso ocorreu provavelmente pela utilização da não sacarose na reativação da sua atividade metabólica.

Figura 4. 'A': Refere-se às médias das formas de colheitas para o parâmetro Pol (\%); 'B': Refere-se à análise de Regressão Linear para o parâmetro Pol (\%) na CF-1; 'C': Refere-se a análise de Regressão Polinomial para o parâmetro Pol (\%) na CF2;' D’: Refere-se a análise de Regressão Linear para o parâmetro Pol (\%) na CF-3
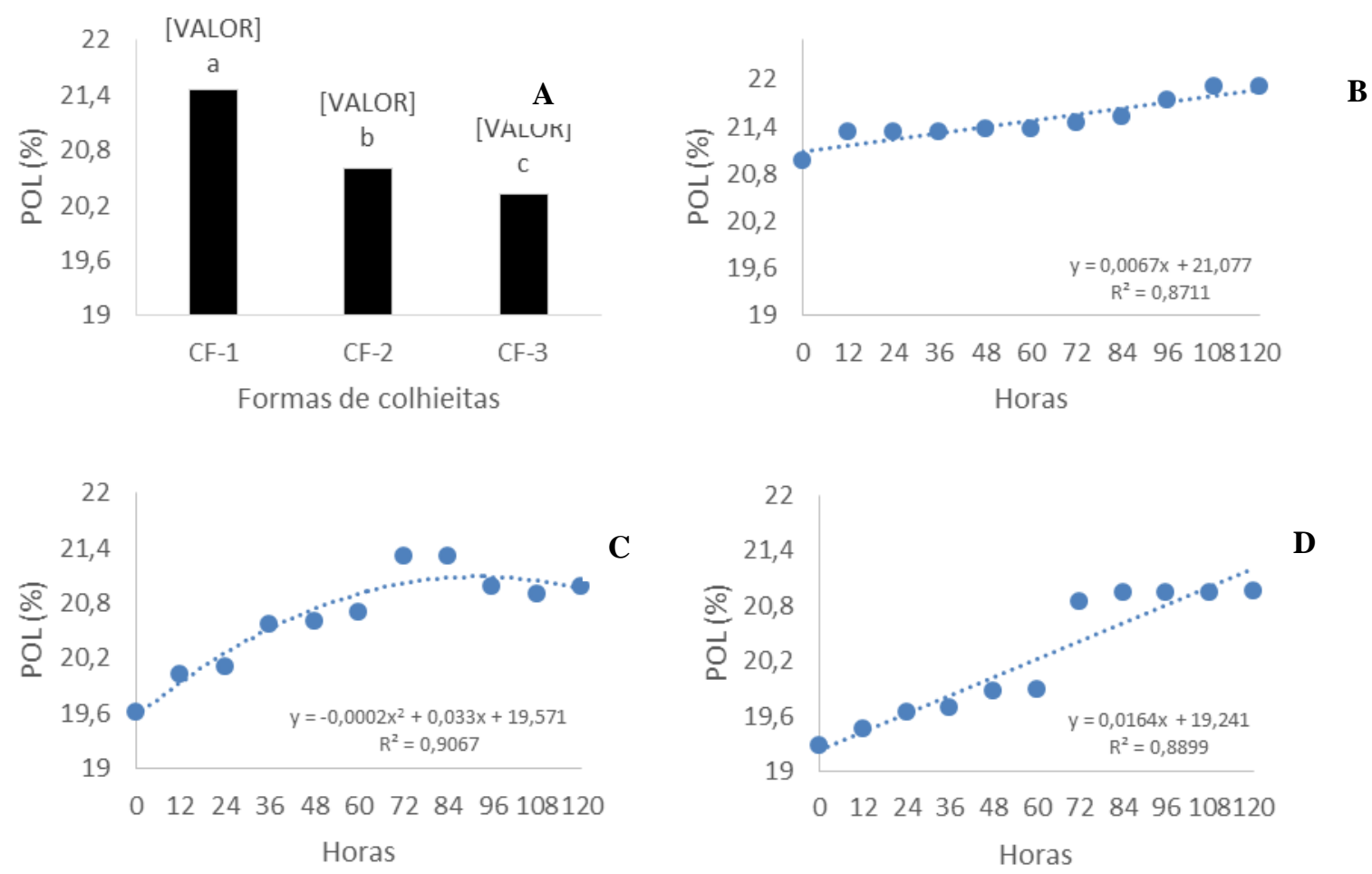

\section{Pureza (\%)}

Analisando a (Figura 5 A) nota-se que não houve diferenças significativas, para o parâmetro Pureza (\%), entre as formas de colheita. Constatando-se, no CF-1, a maior média, 87,14\%. Nas formas de colheita $\mathrm{CF}-2$ e $\mathrm{CF}-3$ obtiveram-se médias de 87,03 e $85,98 \%$, respectivamente.

Os dados da literatura revelam que os valores de Pureza (\%), quando a cana-de-açúcar está adequada para o beneficiamento, devem ser de, no mínimo, $85 \%$ de pureza (FIGUEIREDO, 2010), o que vem a garantir um bom aproveitamento industrial. Silva et al. (2013), estudando qualidade industrial de quatro variedades de cana-de-açúcar em três anos agrícolas verificaram médias para Pureza (\%) de $85,74 \%$ na cana planta, $84,62 \%$ na primeira rebrota e $86,28 \%$ 
durante a segunda rebrota. Segundo Tarso Junior (2007) a alta pureza na cana, observado neste trabalho, é prenúncio de facilidade de açúcar e de altos rendimentos. Verificando-se o associado de baixa quantidade de não sacarose, como componentes normais do caldo, exemplo: aminoácidos, ácidos orgânicos, amido, açúcares redutores, além de outros precursores e formadores de cor (STUPIELLO, 2000).

Analisando a (Figura $5 \mathrm{~B}, \mathrm{C}$ e D) verifica-se o comportamento da pureza em função do tempo para cada forma de colheita, notando-se regressão linear decrescente nas formas de colheita CF-1 e CF-2 (Figura 5 B e C), destacandose um decremento na ordem de $82,14 \%$ para a CF-1 e $85,10 \%$ para a CF- 2. Deve-se salientar que na CF-1 obteve-se há 0 hora, o maior valor de Pureza (\%), no entanto, ocorreu a maior redução, o que significa dizer que, ao ser colhida verde, a cana deve seguir, de imediato, para o processamento. A diminuição da Pureza está relacionada com afastamento dos valores de ${ }^{\circ}$ Brix $(\%)$ e Pol $(\%)$, que indica concentração de não sacarose, que é indesejável para o processamento. Dessa forma os valores do ${ }^{\circ}$ Brix (\%) e da Pol (\%) isoladamente não indica que cana-de-açúcar apresenta-se boa qualidade, quando a mesmo passa tempo de estocagem no campo, necessitando- se avaliação da Pureza (\%) que está relacionado com os dois parâmetros citado.

$\mathrm{Na}$ forma de colheita CF-3, nota-se que ocorreu comportamento quadrático (Figura $5 \mathrm{D}$ ), com máximo em pureza obtido no tempo de $14,8 \mathrm{~h}$, na ordem de $88 \%$, ocorrendo uma redução a partir desse tempo de exposição. $\mathrm{O}$ máximo acúmulo da Pol (\%), não está associado ao melhor ponto de industrialização. Pois o tempo de armazenamento é um ponto negativo, sinônimo de deterioração da matéria prima. Ainda, pode-se dizer que nesse período ocorre a redução no ${ }^{\circ}$ Brix (\%) (Figura $3 \mathrm{D}$ ), ao tempo em que ocorre aumento na Pol (\%), o que pode estar relacionado ao consumo de compostos não sacarose presentes no colmo das plantas. Isso ocorre provavelmente por causa do alto valor do ${ }^{\circ}$ Brix (\%), com isso não foi necessário fazer uso da inversão da sacarose para reativação do metabolismo da planta.

A redução do parâmetro Pureza (\%) está relacionada, diretamente, com o tempo de armazenamento, ocorrendo à diminuição da qualidade com o aumento do tempo. De acordo com Irvine (1993), os colmos de cana-de-açúcar podem se deteriorar mediante processos enzimáticos, com destaque para a ação da enzima invertase, que converte a sacarose em glicose e frutose, promovendo redução da pureza.

Figura 5. A': Refere-se as médias das formas de colheitas para o parâmetro Pureza (\%); 'B': Refere-se a análise de Regressão Linear para o parâmetro Pureza (\%) na CF-1; 'C': Refere-se a análise de Regressão Polinomial para o parâmetro Pureza (\%) na CF-2;' D’: Refere-se a análise de Regressão Linear para o parâmetro Pureza (\%) na CF-3
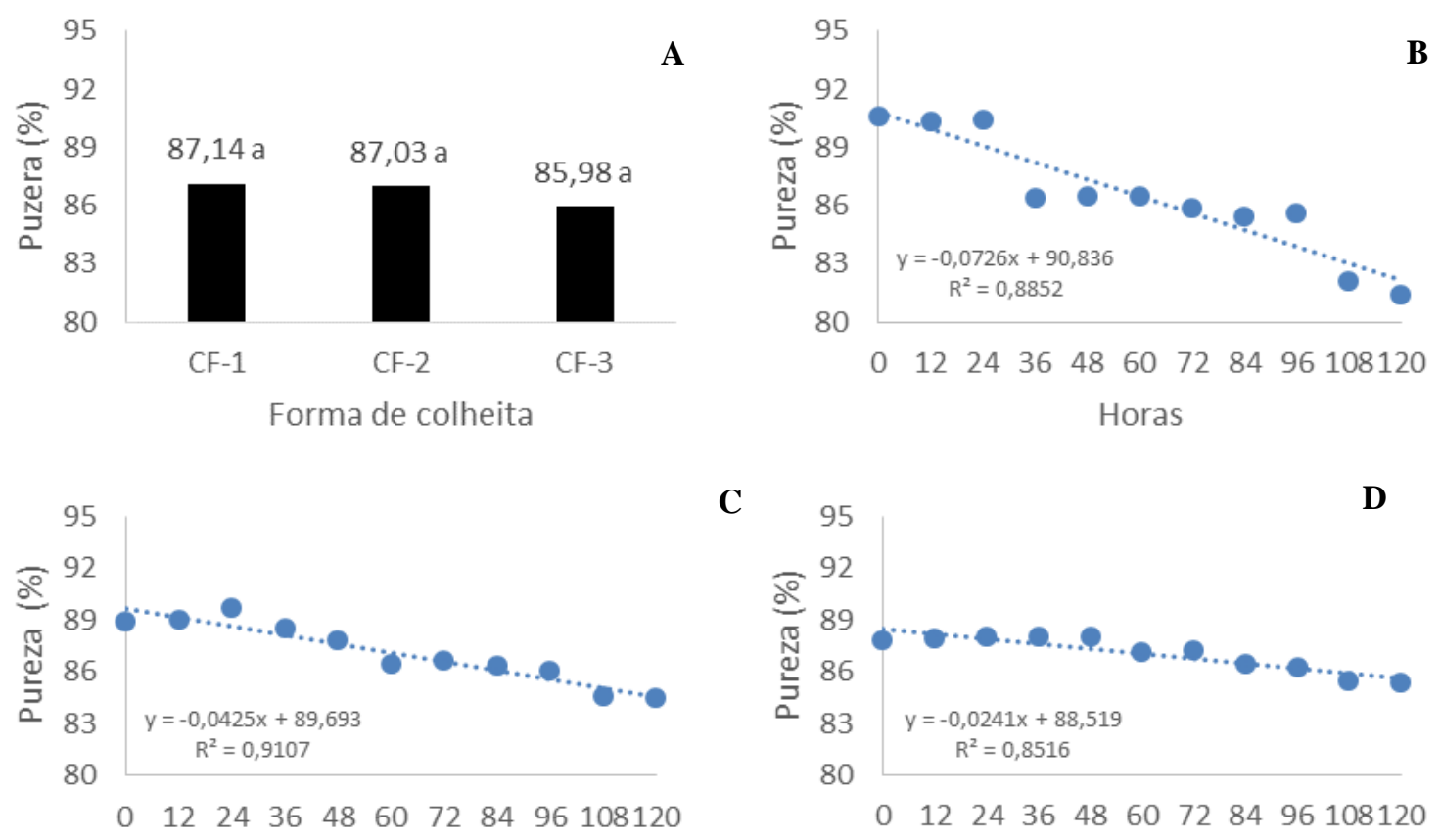

C

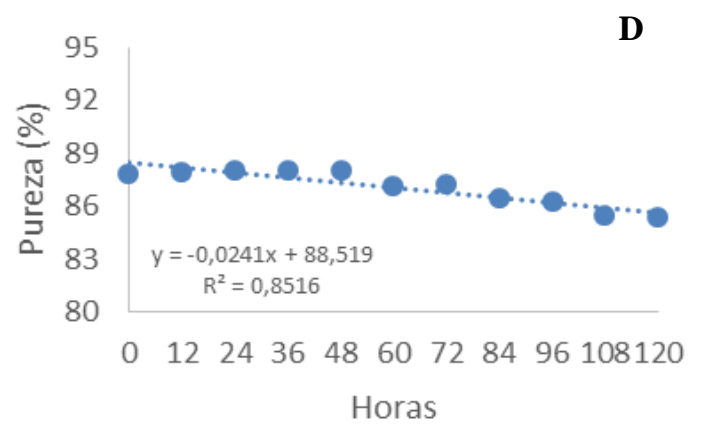

\section{Fibra Industrial (\%)}

Analisando os teores de Fibra (\%), nota-se que houve diferenças significativas entra as formas de colheitas, constatando-se médias entre 12,45\% e 13,00\% (Figura 6 A), sendo que os valores à zero hora não ultrapassaram os $12,20 \%$. Comparando-se com os dados da literatura, nota-se que os valores obtidos neste trabalho são aceitáveis para o processamento agroindustrial que, segundo Ribeiro (2010), o valor da fibra (\%) deve ficar entre 12 e $14 \%$, no intuito de proporcionar uma boa quantidade de caldo, também, uma boa produção de bagaço para ser utilizado nas caldeiras. Silva et al (2013), estudando qualidade industrial de quatro variedades de cana-de-açúcar em três anos agrícolas verificaram médias para Fibra $(\%)$ de $12,76 \%$ na cana planta, $13,46 \%$ na primeira rebrota e $14,91 \%$ segunda rebrota.

Na (Figura 6 B e C) apresenta-se a curva de regressão polinomial e linear para Fibra $(\%)$ com decréscimo máximo ocorrendo as 66 e $72 \mathrm{~h}$ em ordens de 11,97 e 12,90\%. Estes decréscimos não estão relacionados a alterações na fibra botânica, mas provavelmente refere ao decréscimo das 
impurezas. Verificam aumentos nos valores de Fibra (\%) às $96 \mathrm{~h}$, para as duas formas de colheitas, com ordens de $12,23 \%$ para $\mathrm{CF}-1$ e de $13,10 \%$ para $\mathrm{CF} 2$, que obteve valor máximo às $120 \mathrm{~h}$ (Figura $6 \mathrm{~B}$ e C). Este aumento, provavelmente, está associado ao tempo avançado de permanecia no campo, havendo ressecamento do colmo, consequência da perda por evaporação do solvente, que afeta diretamente o peso de bolo úmido no laboratório, que implica diretamente no valor da Fibra (\%). Segundo Marques et al., (2010) quando ocorre o ressecamento nos colmos a uma dificuldades na moagem, aumentando as perdas de sacarose no bagaço. Conforme Tarso Júnior (2007), isso acontece devido a fração do caldo que, uma vez extraída, é reabsorvida pela fibra da cana. Nas formas de colheitas CF-1 e $\mathrm{CF}-2$ são verificados comportamentos positivos por estarem em uma faixa aceitável, proporciona bom aproveitamento industrial.

$\mathrm{Na}$ forma de colheita CF-3 houve um comportamento linear, com poucos acréscimos ao longo do tempo, notando-se valor máximo às $120 \mathrm{~h}$ em ordem de 12,61\% (Figura 6 D). Os valores verificados estão na faixa aceitável, com seu decréscimo e acréscimo para o processamento. Sabendo que haverá perdas na extração do caldo, associada ao teor de Fibra (\%) com reabsorção da sacarose pelo bagaço, mas as perdas aumentam gradativamente com o aumento da porcentagem de fibra, ficando indesejáveis para o processamento agroindustrial da cana-de-açúcar os valores acima de $14 \%$.

Vasconcelos (2010) relata que os valores de Fibra (\%) na variedade de RB 92579 aumentaram com o tempo, iniciando-se com $12,92 \%$ as zero hora e chegando a $14,42 \%$ às 192 horas após a queima/corte/transporte. O mesmo autor relata que a Fibra (\%) da cana aumenta, devido à transpiração do colmo, provocada pela temperatura, em contrapartida, reduz o peso da cana e a umidade. Esse comportamento de acréscimos é verificado em todas as formas de colheitas, quando avaliados os extremos, mas com redução dos valores de Fibra (\%) durante os tempos de avaliações.

Figura 6. A': Refere-se as médias das formas de colheitaspara o parâmetro Fibra (\%); 'B': Refere-se a análise de Regressão Linear para o parâmetro Fibra (\%) na CF-1; 'C': Refere-se a análise de Regressão Polinomial para o parâmetro Fibra (\%) na CF-2;' D’: Refere-se a análise de Regressão Linear para o parâmetro Fibra (\%) na CF-3

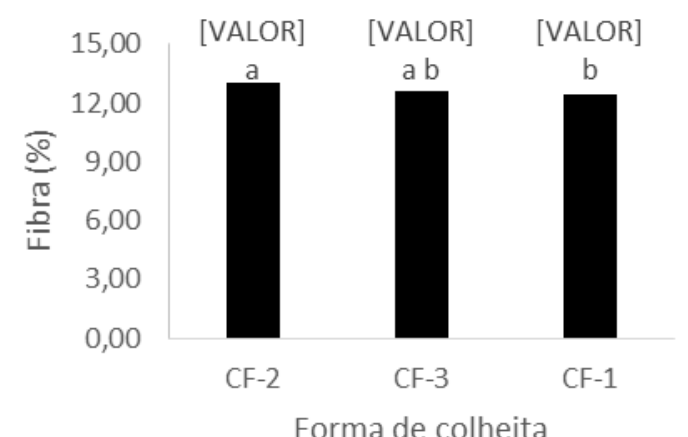

Forma de colheita

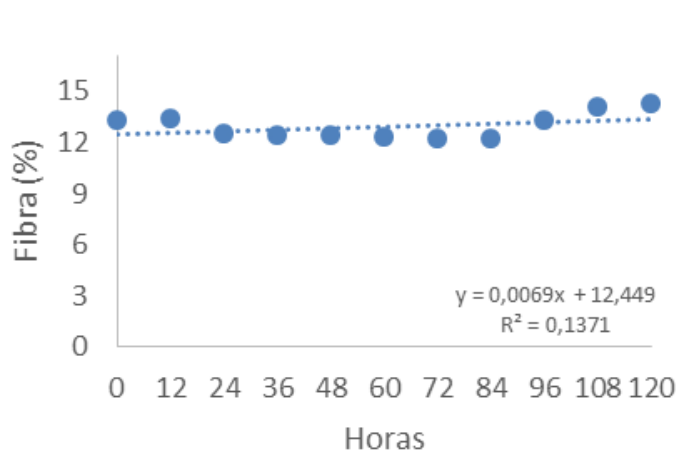

Açúcar Total Recuperável (ATR)

Analisando a (Figura 7), nota-se que houve diferenças significativas entre as formas de colheitas para o parâmetro ATR. A forma de colheita CF-1 obteve média de 171,5 kg/t, seguida do CF-2 com 166,69 kg/t e CF-3 com valor de 163,30 $\mathrm{kg} / \mathrm{t}$.

Na (Figura 7 B, C e D), verificam-se a curva de regressão para o parâmetro ATR, ao longo do tempo com significância à $1 \%$ de probabilidade. Os dados se ajustaram ao modelo linear de regressão e os valores ATR apresentaram uma tendência a crescer, conforme o aumento do tempo de permanência no campo, com isso o maiores valores de ATR foram verificados às $120 \mathrm{~h}$, da matéria prima no campo. Avaliando a (Figura 7 B), verificam-se, na forma de colheita $\mathrm{CF}-1$, os maiores valores de ATR, mas com menor variação

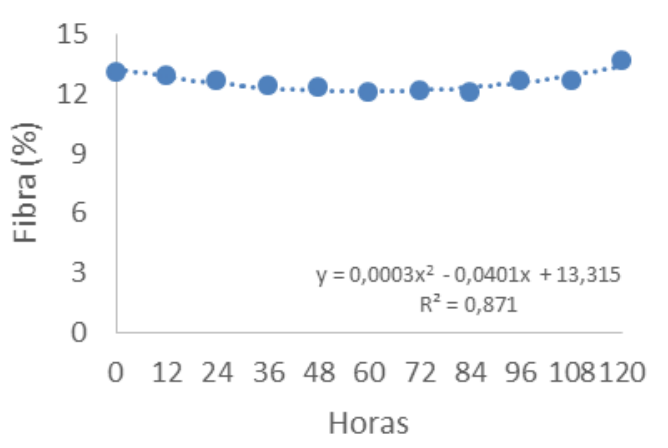

$\mathbf{B}$

D

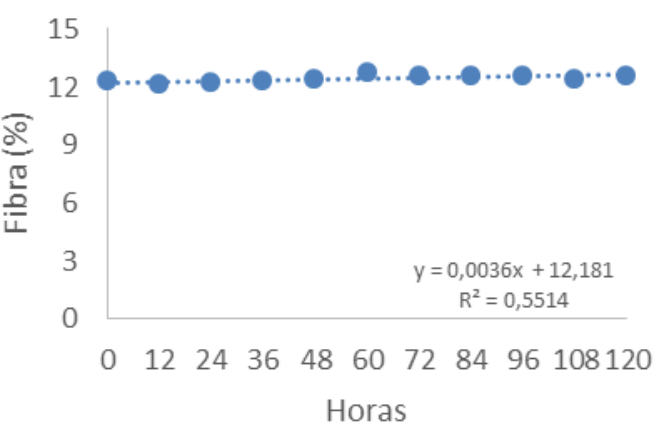

ao longo do tempo. Valores menores com variação maiores foram obtidas nas formas de colheitas CF-2 e CF-3 (Figura 7 $\mathrm{C}$ e D), consequência do processo de queima. Em todas as formas de colheitas houve aumento ao longo do tempo, do parâmetro ATR. Provavelmente esteja associado respiração do colmo e a desidratação, consequentemente a concentração de açúcares.

$\mathrm{Na}$ forma de colheita CF-1, ainda quanto a ATR, verifica-se aumento com dois pontos de estabilidade (48 e 60 h), o acréscimo máximo ocorreu no período de 84 h de ordem de $173 \mathrm{~kg} / \mathrm{t}$ de ATR, este valor não foi alterado até o final do experimento. Nas primeiras $24 \mathrm{~h}$ ocorreu acréscimo $57 \%$ do ATR, com aumento de $4 \mathrm{~kg} \mathrm{~kg} \mathrm{t}^{-1}$. Isso pode ser relacionado a Pureza (\%), que neste período estava superior a $89 \%$, sendo um ponto positivo, pois não é indicado tempo de 
armazenamento prolongados, que acarreta perda de peso do colmo. No trabalho de Valente et al. (2012), houve perda de peso do colmo ao longo do tempo, mesmo sendo armazenamento em galpão, e Vasconcelos (2010) verificou, para variedade RB92579, redução em $0,64 \%$ a $2,34 \%$ por dia de armazenamento, com um perda total de 9,91\% no período de $192 \mathrm{~h}$, ao se estudar a variedade RB867515, no mesmo período da RB92579, verificaram perda de $19,75 \%$ do peso às $192 \mathrm{~h}$.

Figura 7. A': Refere-se as médias das formas de colheitas para o parâmetro ATR; 'B': Refere-se a análise de Regressão Linear para o parâmetro ATR na CF-1; 'C': Refere-se a análise de Regressão Linear para o parâmetro ATR na CF-2;' D': Refere-se a análise de Regressão Linear para o parâmetro ATR na CF-3

A
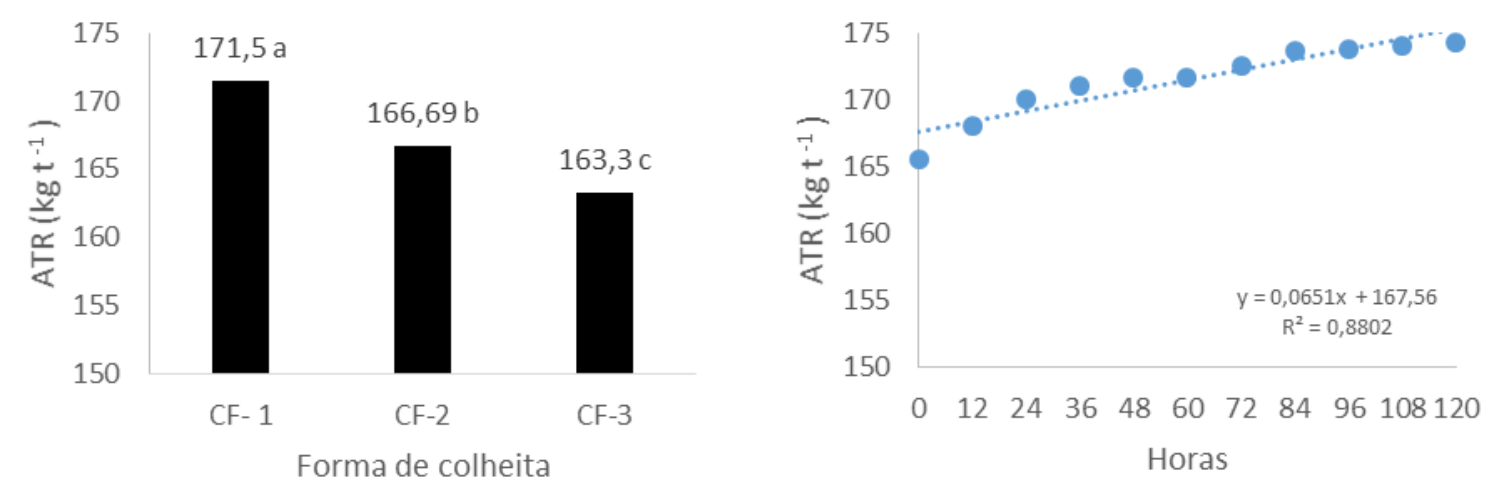

D
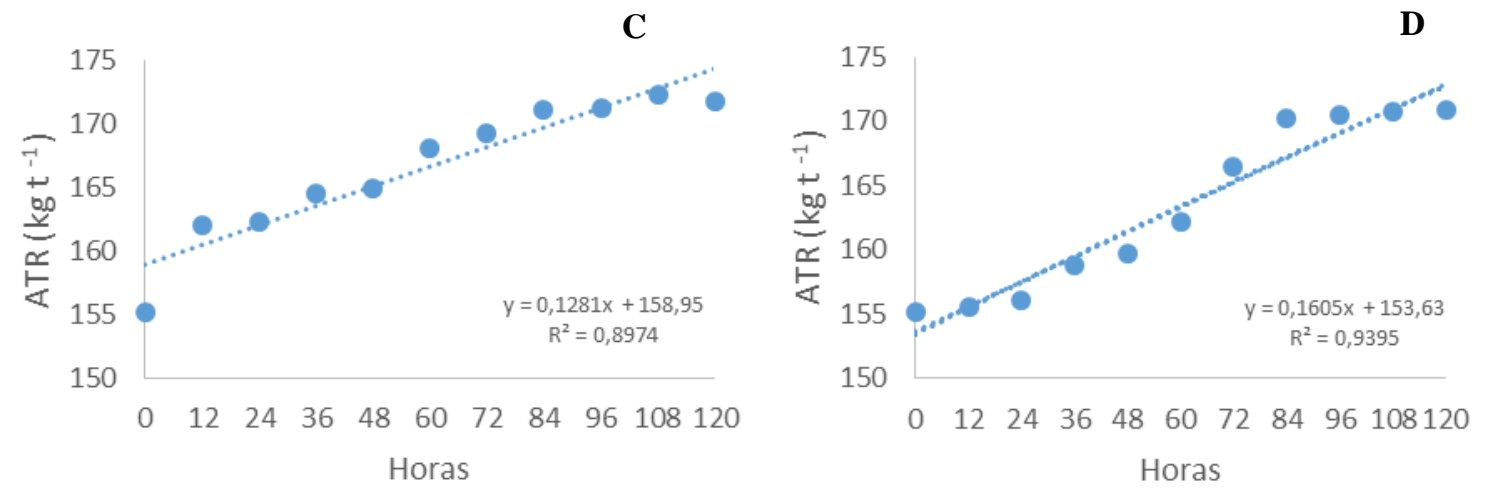

Na forma de colheita CF-2, no parâmetro ATR, verificase um acréscimo simultâneo com o tempo de armazenamento no campo com quatro pequenos pontos estabilidades (12, 36, 84 e 108 h). Verifica-se que os pontos de acréscimo está associado ao período do dia com participação de $94,11 \%$. Os pontos de estabilidades estão associados ao período da noite. Essa forma de colheita teve valor máximo de 172,80 ATR, somando uma acumulo de $14 \mathrm{~kg} / \mathrm{t}$ de ATR, no tempo de 108 h. O ganho de ATR com o tempo é um ponto positivo, mas provavelmente a perca de peso do colmo associado à deterioração da matéria prima com o tempo, torna-se o ganho de ATR, inviável pela indústria.

Para a forma de colheita CF-3 no parâmetro ATR, verifica-se três pontos de estabilidade, tendo uma estabilidade acentuada no início e no final do experimento. Nessa forma de colheita nota-se um acréscimo máximo de $19 \mathrm{~kg} / \mathrm{t}$ de ATR no tempo de $120 \mathrm{~h}$, ocorrendo $62,5 \%$ durante o período do dia.

Neste comportamento de maior acúmulo de ATR no período do dia são verificados no CF-2 e CF-3, os mesmos passaram pelo processo de queima, provavelmente esteja associado às rachaduras provocadas pelo fogo sofrendo perda de água na forma longitudinal do colmo potencializando o acúmulo de açúcares.

\section{CONCLUSÕES}

Os parâmetros ${ }^{\circ}$ Brix (\%), Pol (\%) e ATR isoladamente não indicam perda da qualidade, todavia, quando se faz menção ao tempo de estocagem no campo, é necessário avaliação associado à Pureza (\%).

$\mathrm{O}$ melhor comportamento foi verificado na $\mathrm{CF}-1$, com superioridade nos parâmetros, ${ }^{\circ}$ Brix $(\%)$, Pol (\%), ATR, Pureza $(\%)$, observando valor inferior no parâmetro Fibra $(\%)$.

O melhor tempo entre a colheita e processamento para as formas de colheitas CF-1 e CF-2, foi observado, no período de 36 horas. Nas formas de colheitas que passaram pelo processo de queima, o melhor comportamento foi verificado na forma de colheita CF-2. Na forma de colheita CF-3, foi observado, menores valores na planta, decorrente da reativação do metabolismo fisiológico.

\section{REFERÊNCIAS}

VASCONCELOS. R. R. A. Deterioração da matéria-prima de três variedades de cana-de- açúcar ao longo do tempo no município de Taquarana, estado de Alagoas. 2010 (trabalho de graduação) CECA/UFAL Rio Largo - AL, 2010. 
VALENTE M. C; SILVA N. C; ALVES E. B; OLIVEIRA M. D. B. L; OLIVEIRA I. L; SANTOS J. P; TEIXEIRA W. D.; BERNARDES T. F. Efeito da presença ou ausência de componentes não-colmo e do tempo de estocagem sobre as perdas de massa e concentração de açúcares em cana-deaçúcar, Anais da $49^{a}$ Reunião Anual da Sociedade Brasileira de Zootecnia A produção animal no mundo em transformação Brasília - DF, 2012.

SILVA V. S. G.; OLIVEIRA M. W., SANTOS C. E. R. S.; OLIVEIRA D. C; SILVA C. T; REIS R. M S, Qualidade industrial de quatro variedades de cana-de-açúcar em três anos agrícolas. XIII JORNADA DE ENSINO, PESQUISA E EXTENSÃO - JEPEX 2013 - UFRPE: Recife-PE, 2013.

SIQUEIRA G. R.; ROTH A.P.T.P.; ROTH M.T. P.; Meu canavial queimou, o que eu faço e quanto tempo eu tenho para tomar as devidas providências?,Pesquisa \& Tecnologia, vol. 9 , n. 1, 2012.

SILVA, E.A.; FERREIRA, J.J.; RUAS, J.R.M.; PAES, J.M.V.; MACÊDO, G.A.R.; Utilização da cana-de-açúcar na alimentação de ruminantes. InformeAgropecuário, Belo Horizonte, v.28, n.239, p.102-119, 2007.

SILVA V. S. G.; OLIVEIRA M. W., SANTOS C. E. R. S.; OLIVEIRA D. C; SILVA C. T; REIS R. M S, Qualidade industrial de quatro variedades de cana-de-açúcar em três anos agrícolas. XIII JORNADA DE ENSINO, PESQUISA E EXTENSÃO - JEPEX 2013 - UFRPE: Recife-PE, 2013.

SEGATO, S. V; PINTO. A. S. de; JENDIROBA. E; NÓBREGA. J. C. M. Atualização em produção de cana-deaçúcar. Piracicaba-SP. ND-LIVROCERES, 2006.

STUPIELLO, J. P. Pontas de cana: problema industrial? STAB - Açúcar, Álcool e Subprodutos, Piracicaba, v.18, n.4, p.12, 2000.

Rede Interuniversitária para o Desenvolvimento do Setor Sucroalcooleiro - RIDESA, Catálogo nacional de variedades "RB" de cana-de-açúcar / Rede Interuniversitária para o Desenvolvimento do Setor Sucroalcooleiro. - Curitiba, 2010.

RIPOLI, T.C.C.; RIPOLI, M.L.C. Biomassa de cana-deaçúcar: colheita, energia e ambiente. Editora: Livroceres, 2004, 302p.

RODRIGUES R. C.; SOUZA J. M.; MARQUES H. I. P.; ROBSON B.; SCHMILDT E. R; Produtividade e variáveis agroindustriais de cinco variedades de cana-de-açúcar no norte do espírito santo; ENCICLOPÉDIA BIOSFERA, Centro Científico Conhecer, Goiânia, v.8, n.15; p. 1443 2012.
OLIVEIRA E. C. A.; FREIRE F. J.; OLIVEIRA A. C.; SIMÕES NETO D. E.; ROCHA A. T. e Carvalho L. A. Produtividade, eficiência de uso da água e qualidade tecnológicade cana-de-açúcar submetida a diferentes regimes hídricos. Pesq. agropec. bras., Brasília, v.46, n.6, p.617-625, jun. 2011.

VEIGA FILHO, A. de A. Estudo do processo de mecanização do corte na cana-de-açúcar: o caso do Estado de São Paulo, Brasil. Recife, v. 3, n. 1, p. 74-99, 1999.

TAVARES, A. C. Deterioração da cana-de-açúcar (Saccharumspp.) queimadaem pós-colheita, submetida à aplicação de maturadores químicos. 1997, 63f (Trabalho de Graduação) - FCAV/UNESP, 1997.

AMORIM, H. V. O que é qualidade de matéria prima? In: REUNIÃO AGRÍCOLA DA FERMENTEC, 8, 2003, São Pedro. Resumos Piracicaba: Fermentec, 2003. p. 5-6.

MARQUES JÚNIOR R. B. Uso de ácidos húmicos e bactérias diazotróficas endofíticas na produção de milho e cana-de-açúcar. Tese (Doutorado em Produção Vegetal) Universidade Estadual do Norte Fluminense Darcy Ribeiro, Centro de Ciências e Tecnologias Agropecuárias. Campos dos Goytacazes, RJ, 2010.

KLEIN, V. Características agronômicas, químicas e bromatológicas de variedades de cana-de açúcar para uso forrageiro. Dissertação(Mestrado em Agronomia -Produção Vegetal) - Universidade Federal de Goiás, Goiás, 2010.

FIGUEIREDO. E. M. O. Processos de Desidratação do Álcool. 2010 (Trabalho de graduação) FEQ/UFU- MG, Uberlândia - MG 2010.

TASSO JÚNIOR L. C. Caracterização agrotecnológica de cultivares de cana-de-açúcar (saccharumspp.) na região centro-norte do estado de São Paulo. Tese (Doutorado em Agronomia - Produção Vegetal), FCA/Veterinárias - UNESP, jaboticabal - São Paulo - Brasil, 2007.

IRVINE, J. E. Sugarcane. In: CHEN, J.C.P.; CHOU, C.C. (Ed) Cane Sugar HandBook. A Manual for Cane Sugar Manufactures and their Chemists. New York, John Wiley \& Sons, Inc., 12th ed., 1993.

Caldas, C. Manual de análises selecionadas para indústrias sucroalcooleiras. Maceió: Sindicato da Indústria e do Álcool do Estado de Alagoas, 1998. 424p.

RIBEIRO, E. J. Fermentação Alcoólica. Apostila Módulo II. Processamento na Indústria Sucroalcooleira. Uberaba, FAZU, 2010. 